\title{
EXPANDING THE BOUNDARIES OF SERVICE-LEARNING AT HIGHER EDUCATION THROUGH E-LEARNING SCENARIOS: LESSONS FROM TEACHING INNOVATION PROJECTS
}

\author{
Amalia Creus, Mirela Fiori, Inés Cambra, Nadja Gmelch, Universitat Oberta de Catalunya, \\ Spain
}

\section{Introduction}

Service-learning can be defined as a pedagogical approach that attempts to integrate community service in the academic curriculum. Through service-learning, students engage in organised activities designed to meet community needs and, at the same time, enhance their intellectual, social, and ethical development (Porter Honnet \& Poulsen, 1989). The synergy between learning and civic engagement distinguishes service-learning as an educational approach that, beyond forming students for particular professional skills, has the goal to prepare them for practical community-based problem solving. From a methodological point of view, it places community-improvement and social-engagement in the centre of the learning process, while reinforcing students' cross-disciplinary skills, as critical thinking, cocreation or community building (Billig, Root, \& Jesse, 2005).

Previous research suggests that participation in service-learning is associated with positive outcomes in different areas, among others attitudes toward self, attitudes toward learning, civic engagement, social skills, and also academic achievement (Blank, 1997; Billig, 2009; Conway et al., 2009; White, 2001). Studies on the topic also demonstrate significant increases in students' interest and commitment to their communities, and significant growing in leadership and problem solving (Creus \& Lalueza, 2011; Giles \& Eyler, 1994; Harwood \& Radoff, 2009).

But even though service-learning has been deeply studied and is well recognized as a rich learning tool in face-to-face higher education, less is known about the challenges related to its implementation in an e-Learning context. Following this idea, this paper reports on the process and discusses the preliminary findings of two in-progress innovation projects that explore service-learning as a pedagogical approach in distance education.

\section{Conceptual background}

e-Learning pedagogical models are usually characterised by high flexibility, as a context where students can self-manage time and places of study, generally following an asynchronous and previously defined calendar of tasks and assignments. These aspects, which represent an important asset of e-learning models based on the personalisation of learning itineraries, can 
become problematic when - as happens at service-learning approaches - the learning experience of students is affected by the unpredictability and the complexity implicit in connecting the learning process with the times and needs of external agents.

Nevertheless, e-learning can also provide an opportunity to explore new approaches to service-learning. Approaches that can be distinguished, for instance, by major numbers of collaborative scenarios or by a potentially widespread interaction between a greater diversity of actors. In short, an opportunity to break the boundaries of traditional learning settings by taking advantage of the wide range of possibilities offered by virtual learning environments based on digital and interactive technologies.

Indeed, several authors have drawn attention to the fact that new digital technologies are promoting radical changes in learning (Seely Brown \& Alder, 2008; Cobo \& Moravec, 2011). This is related to the fact that in our network societies the abundance and dispersion of information exists alongside the proliferation of personal devices, spaces, and strategies for the production and dissemination of knowledge that goes beyond educational institutions (Lalueza \& Creus, 2013). From the perspective of professional training, universities face the challenge of preparing students to succeed in a social and labour environment that is constantly changing, where employees are becoming increasingly mobile (Sullivan, 1999; Eby et al., 2003; Baruch, 2003; Briscoe et al., 2006) and where professional success is strongly linked to the ability to pass through different scenarios, learn continuously, and enhance professional networks.

Another remarkable aspect is the role that Internet and social media have nowadays as a space for personal and professional development. As Benson and others remark, graduates who are starting their professional career are expected to be comfortable with interactions using social networks and to be proficient in handling electronic media to work in a team, build social capital and share knowledge (Benson et al., 2010). In fact, looking to the emergence of digital technologies from this broader perspective, Luther and others state that online creative collaboration may be one of the most remarkable consequences of the increased access to information technology. As the same authors argue, examples such as Wikipedia and opensource software projects are turning online creative collaboration into an evolving phenomenon that needs to be studied in depth (Luther et al., 2009).

However, beyond the impact that the aforementioned social and cultural changes have on professional training, it is also important to pay attention to how this very same scenario is affecting the third mission of universities, which includes the aim to prepare new generations to impact on the quality of life of their community (Coffield, 1994). A commonly-used concept in this context is Education for Sustainable Development (ESD) that, following the definition of UNESCO, aims to empower and equip current and future generations to meet their needs using a balanced and integrated approach to the economic, social and environmental dimensions of sustainable development (Leitch et al., 2018). 
Following this aim, the two innovation projects presented in this paper explore different ways to enhance social production of knowledge through e-learning. Based on former collaboration between university degree courses and non-profit organisations, both innovation projects have as an ultimate aim to enhance the contribution of universities to society and sustainable development, while providing students with a meaningful and professional significant learning experience.

\section{Project context}

The Universitat Oberta de Catalunya (UOC) is an online university whose mission is to provide people with lifelong learning and education by designing learning activities using advanced technological and communication resources, some of which include: social tools that facilitate collaborative work, multimedia content, advanced communication systems (both synchronous and asynchronous) and access to learning through mobile devices. Furthermore, a distinctive trait of UOC's educational model is the promotion of collective knowledge-building through an interdisciplinary and open approach to students' educational, social, and working experience (Gros, 2009). This is achieved by incorporating collaborative learning methodologies that involve problem-solving, collective development of projects, joint creation of products (Lalueza \& Creus, 2013) and cooperative research.

In this framework, we highlight the development of two specific teaching innovation projects, both designed from a service-learning perspective: "L'Agència", an online communication agency managed by students, and a more recent initiative named "Participatory Final Degree Projects” (P-FDP) implemented in different bachelor's and master's degrees at UOC.

\section{Project 1}

"L'Agència" is a virtual platform in which students have the opportunity to develop communication projects, experiencing authentic professional dynamics and issues. Moreover, they do so from a perspective of social commitment based on voluntary participation, as the projects are developed for free to non-profit organisations. This virtual agency was created in 2012 and since then more than 100 students have taken part in its activities. This teaching innovation project is being carried out in the context of a Communication Degree course that prepares students with the necessary skills to design, plan, implement, and evaluate communication projects.

\section{Project 2}

Through "Participatory Final Degree Projects" students have the opportunity of developing their degree or master final dissertation focusing on a specific social need of their community, and working in collaboration with a non-profit organisation or a social entrepreneurship. Departing from needs and challenges identified by different organisations, students are invited to develop research questions through a participatory research. 


\section{Topics for discussion}

The specific objective of this paper is to share the preliminary results of a study focused on the above-mentioned teaching innovation projects, both of them based on a service-learning approach. Our main aim is the comprehension of participants' experience, paying special attention to the patterns of interaction generated among students and non-profit organisations. Interactions here can be understood as the set of cognitive and social actions that takes place among the actors in the educational process.

Another question that we will explore in our presentation is how participants' experience is supported and/or constrained by the e-Learning technological environment. Among others, some of the preliminary results that will be discussed in that respect are the followings.

\section{The selection of social tools that adequately support collaboration between students and non-profit organisations}

The relationship that our students have with technology is "natural", pragmatic, and socialoriented. Universities are now welcoming the first generations of students who were born and raised in the digital age. It is a new generation of learners who have grown up along with the development of the Internet and who see digital technologies and social networks as a "naturalised" dimension of their professional and social life. To engage this profile of students in any activity where they are expected to take the lead requires a usable, accessible and nonhierarchical virtual environment (by non-hierarchical we mean an environment where users have high levels of administration permissions). In fact, it is noteworthy that students often tend to resolve questions and problems of a technical nature among their peers, rather than resorting to formal tutorials or technical support services. It is also significant that the diversity of media that students know and use every day makes it easier for them not to remain restricted to established resources and to embrace technological alternatives "outside the system", especially in regard to mobile communication. In that respect, the design of a successful collaboration must consider the inclusion of a decentralised selection of media and technologies, leaving room to incorporate developments in the learning process that occur outside the domain of the formal e-Learning environment.

\section{The importance of rethinking the nature of "presence" and leadership in virtual collaboration}

Several authors stress the idea that virtual groups afford a great opportunity to redefine leadership. According to the traditional model, leaders are supposed to offer encouragement, reward and motivation, and reinforce the development of relations inside the group (Ruggieri et al., 2013). Where in face-to-face situations the physical presence is a significant strategy for leaders, virtual collaboration makes it necessary to rethink some aspects of leadership. One of the more remarkable characteristics of this new context is the recognisability of the leader's status. As Ruggieri and others maintain, in face-to-face interactions leadership indicators involve body language, vocal inflection, eye contact, clothing, etc. However, virtual media forces the leader to adopt other indicators to let followers know that they are in charge. These 
indicators, as we can observe, include, among others, frequency of interventions, short delays between request and response, and availability to answer questions and help colleagues. The analysis of the projects also showed that effective leadership has much to do with the leader's ability to influence the emotional climate of the group. Messages of motivation, the capacity to express empathy or interest in the work of others as well as the ability to post messages that drive colleagues to action without generating conflict are almost always more effective than just having knowledge of the subject. In that sense, while the role assumed by teachers and non-profit organisations tends to be recognised as the "established authority" which is in charge of validating and assessing the quality of the work developed, students who emerge as natural leaders among their peers tend to make a substantial difference to the formation and sustainability of a successful team collaboration.

\section{Final remarks}

This study enables us to understand in depth the role that technology plays in shaping collaboration among the participants (students, teachers and non-profit organisations). Emergent results call our attention to the importance of moving the focus of the environment's design from the technology itself to the interactions generated by the users, who usually appropriate it in unexpected ways.

The study also addresses the importance of constant and progressive feedback as a key factor to ensure shared objectives and evaluation of results. This leads us to the need to further analyse the impact of the service-learning approach focusing on students' motivation and learning and also in its benefits from the participant organisations' point of view.

Finally, the study allows us to identify the need to develop more flexible assessment tools and better methodologies to evaluate virtual collaboration in service-learning, taking into account the different levels of participation, social roles, individual expertise, and the ability of students to take cooperative decisions and manage conflict. These are some of the questions we want to address in further developments of our research.

\section{References}

Benson, V., Filippaios, F., \& Morgan, S. (2010). Online Social Networks: Changing the Face of Business Education and Career Planning. International Journal of e-Business Management, 4(1).

Billig, S. H. (2009). Does quality really matter: Testing the new K-12 service- learning standards for quality practice. In B. E. Moely, S. H. Billig, \& B. A. Holland (Eds.), Advances in service-learning research: Vol. 9. Creating our identities in service-learning and community engagement (pp. 131-158). Greenwich, CT: Information Age.

Billig, S. H., Root, S., \& Jesse, D. (2005). Impact of Participation in Service-Learning on High School Students' Civic and Academic Engagement. Report to the Carnegie Corporation of New York. Denver: RMC Research Corporation. 
Blank, W. (1997). Authentic Instruction. In W. E. Blank \& S. Harwell (Eds.), Promising Practices for Connecting High School to the Real World (pp. 15-21). Tampa: University of South Florida.

Briscoe, J., Hall, D., \& Frautschy DeMuth, R. (2006). Protean and Boundaryless Careers: An Empirical Exploration. Journal of Vocational Behaviour, 69(2006), 30-47.

Cobo, C., \& Moravec, J. (2011). Aprendizaje Invisible. Hacia una Nueva Ecología de la Educación. Barcelona: UBe.

Coffield, F. (1994). Research specification for the ESRC Learning Society Research Programme. Swindon: ESRC.

Conway, J. M., Amel, E. L., \& Gerwien, D. P. (2009). Teaching and learning in the social context: A meta-analysis of service learning's effects on academic, personal, social, and citizenship outcomes. Teaching of Psychology, 36, 233-245.

Creus, A., \& Lalueza, F. (2011). Learning through Professional Environments: The ComCity Project. eLearn Center Research Paper Series, 5, 32-40.

Eby, L. T., Butts, M., \& Lockwood, A. (2003). Predictors of Success in the Era of the Boundaryless Career. Journal of Organizational Behavior, 24, 689-708.

Eyler, J., Giles, D. E., Stenson, C. M., \& Gray, C. J. (2001). At-a-glance: What we know about the effects of service-learning on students, faculty, institutions, and communities, 19932001. Retrieved June 15, 2009, from the National Service-Learning Clearinghouse website: http://www.servicelearning.org/pubs/materials/L054

Harwood, A. M., \& Radoff, S. A. (2009). Reciprocal benefits of mentoring: Results of a middle school-university collaboration. In B. E. Moely, S. H. Billig, \& B. A. Holland (Eds.), Advances in service-learning research: Vol 9. Creating our identities in service-learning and community engagement (pp. 131-158). Greenwich, CT: Information Age.

Lalueza, F., \& Creus, A. (2013). Prácticas Reales en Entornos no Presenciales: La Agencia Virtual de Comunicación como Herramienta de Aprendizaje Profesionalizador. Historia y Comunicación Social, 18(spec. 2013), 199-211.

Leicht, A., Heiss, J., \& Byun, W. J. (2018). Issues and trends in Education for Sustainable Development. Paris: UNESCO Publishing. Retrieved from https://unesdoc.unesco.org/ark:/48223/pf0000261445

Luther, K., Counts, S., Stecher, K. B., Hoff, A., \& Johns, P. (2009). Pathfinder: an online collaboration environment for citizen scientists. CHI 2009.

Porter Honnet, E., \& Poulsen, S. (1989). Principles of good practice for combining service and learning. Wingspread Special Report. Racine, WI: The Johnson Foundation.

Ruggieri, S., Boca, S., \& Garro, M. (2013). Leadership Styles in Synchronous and Asynchronous Virtual Learning Environments. The Turkish Online Journal of Education Technology, 12(4), 96-102. 
Expanding the Boundaries of Service-Learning at Higher Education through e-Learning Scenarios: Lessons from Teaching Innovation Projects

Amalia Creus et al.

Seely Brown, J., \& Alder, R. (2008). Minds of Fire. Open Education, The Long Tail and Learning 2.0. Educause, 17-32.

Sullivan, S. E. (1999). The Changing Nature of Careers: A Review and Research Agenda. Journal of Management, 25(3), 457-484.

Sutherland, R., Eagle, S., \& Joubert, M. (2012). A Vision and Strategy for Technology Enhanced Learning: Report from the Stellar Network of Excellence. Bristol, UK, 60.

White, A. (2001). Meta-analysis of service-learning research in middle and high schools (Unpublished doctoral dissertation). University of North Texas, Denton. 